\title{
A pesquisa em educação: um balanço da produção dos programas de pós-graduação*
}

\author{
Paolo Nosella
}

Universidade Federal de São Carlos, Programa de Pós-Graduação em Educação

\section{As pesquisas em educação antes da criação dos programas de pós-graduação em educação}

A produção da pesquisa em educação anterior à criação dos programas de pós-graduação desenvolviase em reduzidas dimensões em algumas instituições universitárias, como na antiga Seção de Pedagogia da Faculdade de Filosofia, Ciências e Letras da Universidade de São Paulo (FFCL/USP) e em outras instituições criadas exclusivamente para essa finalidade. Em 1955, essa produção recebera grande impulso com a criação do Centro Brasileiro de Pesquisas Educacionais (CBPE) e dos cinco centros regionais de pesquisa criados pelo Instituto Nacional de Estudos e Pesquisas Educacionais Anísio Teixeira (INEP), na gestão de Anísio Teixeira. Consequências importantes dessa integração foram o incremento do número de pesqui-

* Este texto tomou como base o relatório enviado ao CNPq em 2008, intitulado Instituições escolares: por que e como pesquisar, redigido em coautoria com a professora doutora Ester Buffa (Campinas: Átomo \& Alínea, 2009). sas em educação e seu caráter político, sociológico e histórico, que marcou as pesquisas em educação dessa época e que podemos sintetizar com a expressão educação e sociedade.

Dois fatores relevantes contribuíram para essa caracterização política:

a) o processo de elaboração da Lei de Diretrizes e Bases da Educação Nacional, aprovada em 1961

b) a expansão do ensino superior pelo interior do estado a partir de 1950, com a criação dos institutos isolados de ensino superior (futura Universidade do Estado de São Paulo - UNESP) e, a partir de 1964, pelo Brasil inteiro, com a criação, sobretudo, da rede de universidades federais.

É fácil imaginar como esses dois fatores criavam um ambiente efervescente de debates e publicações sobre a realidade educacional brasileira e a problemática da democratização do ensino. Dessa época, são sempre lembrados os nomes de professores como Fernando de Azevedo, Anísio Teixeira e Lourenço Filho, entre os signatários do Manifesto de 1932, bem como os 
nomes de Laerte Ramos de Carvalho, José Mário Pires Azanha, João Eduardo Rodrigues Villalobos, Maria de Lourdes Mariotto Haidar, Casimiro dos Reis Filho, Rivadávia Marques Júnior e Jorge Nagle, entre muitos outros.

Como já mencionado, o grande tema de pesquisas desse período, e não apenas em São Paulo, era educação e sociedade, isso por influência, sobretudo, da sociologia e das ciências sociais em geral, cientificamente prestigiadas e em ascensão na época. São emblemáticos, nesse sentido, os nomes dos conhecidos "pioneiros da educação": Fernando de Azevedo, Anísio Teixeira e Lourenço Filho, entre outros, signatários do Manifesto de 1932. Entretanto, como diz Leonor Tanuri (2005, p. 159-160), também nessa época eram realizados alguns estudos, poucos, sobre temas mais particulares da educação, como sobre instituições de ensino:

\footnotetext{
José Ferreira Carrato foi um dos poucos historiadores na época a se dedicar à história cultural e educacional, pois, em 1961, apresentou tese de doutoramento sobre as origens do Colégio Caraça, intitulada As Minas Gerais e os primórdios do Caraça, e, em 1968, publicou Igreja, iluminismo e escolas mineiras coloniais. [...] O trabalho de Maria Aparecida Rocha Bauab, acompanhado de arrolamento de fontes escritas e de recursos iconográficos, analisou as dificuldades de implantação e as vicissitudes da única escola normal criada no período imperial em São Paulo.
}

\section{As pesquisas dos programas de pós-graduação em educação nos primeiros 20 anos (1965-1985)}

A criação da pós-graduação nas universidades brasileiras da forma institucionalizada como hoje a conhecemos, priorizando as atividades de pesquisa, deve ser atribuída à modernização autoritária e conservadora dos governos militares. Por uma das frequentes ironias da história, o feitiço voltou-se contra o feiticeiro, isto é, a ditadura criou uma estrutura escolar que produziu consequências políticas e culturais em boa parte contrárias aos objetivos dos criadores. Com efeito, apesar da orientação tecnicista, conservadora, repressora da política educacional daqueles governos, as pesquisas produzidas pelos programas de pós-graduação cada vez mais criticavam o sistema que os criou.

Duas características fundamentais qualificaram as pesquisas em educação dos primeiros vinte anos de vigência dos programas de pós-graduação (19651985): a institucionalização escolar da produção da pesquisa, que exacerbou a burocratização do trabalho científico, e a reação aos militares, que propiciou o desenvolvimento de um forte pensamento crítico.

Essas duas características têm aspectos positivos e negativos. O principal aspecto positivo da escolarização da pós-graduação manifesta-se no fato de que a produção do conhecimento (pesquisa) se associou às atividades de ensino. Seu aspecto negativo é representado pelo burocratismo acadêmico que nivela, pelos títulos e diplomas, pesquisas de qualidade com outras menos significativas.

Quanto ao desenvolvimento do pensamento crítico, destaca-se como ponto positivo a leitura pelos educadores desse momento de importantes autores clássicos, como Marx, Gramsci, Althusser, Foucault, Adorno, Bourdieu e outros que fecundaram o pensamento pedagógico por meio de categorias até então desconhecidas. Temas como sociedade de classes, base material da sociedade, atividade ideológica, compromisso político e competência técnica, democratização da escola, reprodução simbólica eram considerados os mais legítimos.

Infelizmente, os estudos críticos desse momento muitas vezes se reduziam a visões genéricas e paradigmáticas, frequentemente muito ideológicas e pouco voltadas aos objetos específicos da educação. Eram estudos que refletiam acentuado idealismo e voluntarismo político decorrentes da urgência do processo de redemocratização.

\section{As pesquisas dos programas de pós-graduação em educação pós-ditadura (1985-2008)}

O período que vem de 1985 até hoje, historicamente configurado pela volta da democracia, é mar- 
cado pela consolidação e expansão da pós-graduação. O retorno da democracia formal significou para todos começar a viver uma situação política e ideológica ambígua. Por vinte anos caminhamos teoricamente seguros e unidos, guiados pela bandeira unitária da luta contra a ditadura militar. A Nova República, infelizmente, não garantiu a realização dos sonhos de muitos, e a distinção entre direita e esquerda já não era tão nítida. Era a crise das utopias e dos paradigmas, no Brasil e no mundo, sobretudo após a queda do Muro de Berlim em 1989.

Muitos estudiosos criticavam as pesquisas sobre sociedade e educação por serem ideológicas e não conseguirem abarcar a complexidade e diversidade do real. Assim, partiram para a proposta de um pluralismo epistemológico e temático, privilegiando o estudo de objetos singulares da educação.

$\mathrm{O}$ aspecto positivo da produção de pesquisas desse momento é representado pela ampliação das linhas de investigação, pela diversificação teórico-metodológica e pela utilização das mais variadas fontes, mas houve também uma fragmentação epistemológica e temática que tem dificultado a compreensão da totalidade do fenômeno educacional. Há quem veja nessa crise paradigmática um movimento antimarxista e o abandono da perspectiva histórica.

São privilegiados temas como cultura escolar, formação de professores, livros didáticos, disciplinas escolares, currículo, práticas educativas, questões de gênero, infância e instituições escolares. A nova história, a história cultural, a nova sociologia e a sociologia francesa constituem importantes matrizes teóricas das pesquisas realizadas dos anos 1985 para cá.

Por se tratar de uma nova tendência metodológica de pesquisa, é oportuno efetuar um balanço crítico com o objetivo de verificar em que medida tais estudos têm contribuído para uma objetiva compreensão da educação, com vistas a sua transformação.

Uma primeira constatação é que todas as pesquisas agora são acadêmicas, a maior parte delas constituída por dissertações de mestrado e teses de doutorado e pós-doutorado. Esse fato evidencia quem fala - professores e pós-graduandos - e o lugar de onde se fala - a academia, em especial os programas de pós-graduação. Por isso, tais investigações se revestem de natureza específica, pois seguem os critérios e são resultados das condições de produção escolar da pós-graduação, a qual pretende ser rigorosa, uma vez que o rigor é exigência do saber científico; todos sabemos, porém, quase nunca é realizada em condições ideais. As dissertações, principalmente, apresentam deficiências de escrita, reflexo da precária escolarização básica e das dificuldades com o próprio fazer da pesquisa: o tempo curto, escassez e exiguidade de bolsas, acúmulo de estudos com o trabalho, falta de arquivos e de boas bibliotecas.

Como se isso fosse pouco, há ainda a pressão das agências de fomento (embora, sem elas, as coisas poderiam ser muito piores) e das que avaliam os programas. A pressão produtivista é enorme e estressante. Assim, publica-se de forma ansiosa todo tipo de texto em periódicos ou apresenta-se paper em congressos, já chamados no jargão acadêmico de "qualisficados", numa referência ao Qualis, programa que classifica em diferentes níveis de qualidade e prestígio as publicações e os eventos de cada área de conhecimento.

Tanto nas bancas de defesa e nos eventos científicos, quanto nas conferências e mesas-redondas, que contam com a presença de pesquisadores nacionais e estrangeiros, há apresentação de resultados de pesquisa ou mesmo de pesquisas em andamento por parte de mestrandos, doutorandos, alunos de graduação, às vezes com bolsa de iniciação científica, e de professores universitários. $\mathrm{O}$ que se quer frisar é que toda essa produção, tanto a destinada à obtenção de títulos de mestre e doutor como a apresentada em eventos científicos e, ainda, os artigos publicados em periódicos e livros, é essencialmente acadêmica. Isso significa que os textos produzidos trazem as marcas, positivas e negativas, da escolarização pós-graduada.

Há, contudo, pesquisadores mais amadurecidos e criativos, com experiência em ensino e pesquisa, que dão uma contribuição efetiva para melhor compreensão da educação brasileira e, assim, quem sabe, contribuem para sua transformação. Esses são, geralmente, autores conhecidos, que, nos seus escritos, 
focalizam as questões de fundo, sobretudo as questões teórico-metodológicas da pesquisa. Este é um aspecto altamente positivo da produção acadêmica.

Há outros aspectos positivos: mesmo quando a produção é mais reiterativa do que inovadora, os pesquisadores acabam organizando algum acervo documental da educação, cuja problemática estão levantando e cuja memória estão recuperando. Todos sabem em que condições se encontram muitos documentos, livros e revistas antigos: depositados em salas que não apresentam condições de uso, às vezes em copas ou banheiros quebrados, disputando espaço com poeira, ácaros, restos de material inútil etc. Há pesquisadores que estão higienizando e organizando a documentação do arquivo de escolas, muitas vezes com apoio de agências de fomento à pesquisa, preservando assim o que resta da memória. Destacam-se, ainda, a organização de material iconográfico, de objetos e móveis escolares e a produção de documentos a partir de entrevistas realizadas com atores significativos da educação, como ex-dirigentes, ex-professores, ex-alunos etc. Todo esse trabalho tem colocado documentos importantes para o conhecimento da nossa escola em condições de consulta por vários outros pesquisadores - o que é muito importante.

Por tudo isso, mesmo com as limitações apontadas, deve-se reconhecer que o mundo acadêmico, a partir dos anos 1985, produziu um conjunto de pesquisas cujo valor social e cultural é notável. Mais ainda: os programas de pós-graduação em educação estão difundindo uma cultura de pesquisa que aos poucos contamina positivamente o sistema escolar brasileiro.

\section{Desafios atuais dos programas de pós- graduação em educação na produção das pesquisas}

Consideramos que a pesquisa dos programas de pós-graduação em educação enfrenta, entre outros, os seguintes desafios: revigorar a teoria, melhorar as narrativas, rever o processo de avaliação, institucionalizar a pesquisa nas novas universidades. Farei um comentário para cada tópico. a) Revigorar a teoria

O pensamento débil e fragmentado do PósModernismo não pode seduzir-nos. Os vinte anos de resistência à ditadura nos educaram para o debate robusto entre pensamentos fortes, para a polêmica, para as dúvidas corajosas. Por isso, o que mais me interessou verificar nas pesquisas realizadas ultimamente foi o referencial teórico e os procedimentos metodológicos utilizados pelos pesquisadores. Isso exigiria, naturalmente, leitura atenta dos numerosos estudos realizados. A leitura de vários deles publicados e dos resumos de muitos outros revelou alguns indícios importantes quanto ao referencial teórico adotado.

Frequentemente, há justaposição entre o referencial teórico proclamado e o posto em prática, isto é, falta organicidade entre o referencial teórico e os dados empíricos coletados. Assim, na consideração dos aspectos empíricos, indispensável etapa do processo de investigação, escapa o movimento real da história, que às vezes foi exposto como independente da materialidade dos aspectos singulares, ou seja, o ponto mais delicado da questão teórica é organizar os dados empíricos, para que deles emerja o sentido do todo. Mas, para organizar esses dados, é preciso possuir uma linha, uma direção, uma ideia geral que costure os fragmentos da existência e da história. Essa linha ou ideia geral é, diz Manacorda (2007, p. 12), citando Marx, "o trabalho do homem, em colaboração com os outros homens, para dominar a natureza e humanizá-la. Esta sempre foi a raiz da história”.

Obviamente, não existe só a linha vermelha ou o humanismo radical. Existem outras linhas: azul, verde, lilás, amarela etc., isto é, existem outras tendências teóricas, fecundas e esclarecedoras da realidade, como sabemos. O essencial é que o pesquisador tenha uma linha séria e precisa que, como o fio de Ariadne, lhe permita sair do labirinto da irracionalidade ou do solipsismo. Dessa forma, o próprio trabalho de pesquisa revigora o debate teórico e neutraliza a decadência das brigas setoriais pelo micropoder.

Com essa linha teórica, o pesquisador estuda e reconstrói o real, passado ou presente, numa perspec- 
tiva cultural de valores próprios, avaliando pessoas e instituições. Elabora, assim, uma síntese original entre o nível êmico e o nível ético, isto é, após distinguir o que pensam e fazem outras pessoas em circunstâncias diferentes do que pensa e faz ele próprio, fazer uma integração entre os dois níveis. Assim, cria-se uma realidade totalmente original, quase uma ficção; melhor dizendo, cria uma pesquisa que é uma obra de arte, pequena ou grande que seja, mas sempre rica de sentido.

Contudo, trata-se de uma obra (o relatório final) que não é uma construção arbitrária, menos ainda uma mentira, pois tem as fontes como base. Tampouco é uma reprodução mecânica de algo que está fora dele. É uma obra de cultura enraizada, de um lado, em fontes e valores alheios; de outro, em valores pessoais, em defesa de um próprio projeto social.

Com base nessa concepção geral teórico-política, a pesquisa começa sempre com uma minuciosa descrição do particular, explicitando suas relações com o contexto econômico, político, social e cultural. Ou, como disse Marx (1983, p. 20), em 1873, no "Posfácio à segunda edição" de $O$ capital, o pesquisador, antes de expor o movimento real na sua totalidade, precisa investigar os aspectos particulares do real, condizentes com os valores e o sentido que ele atribui à história:

\section{É, sem dúvida, necessário distinguir o método de exposição formalmente do método de pesquisa. A pesquisa tem de cap- tar detalhadamente a matéria, analisar as suas várias formas de evolução e rastrear sua conexão íntima. Só depois de concluído esse trabalho é que se pode expor adequadamente o movimento real.}

\section{b) Melhorar as narrativas}

Pode parecer um aspecto secundário, mas não é. A narrativa conclusiva é resultado de um ato complexo, às vezes demorado e quase sempre sofrido. Contém elementos científicos e técnicos, mas também literários. Há pesquisadores que não atribuem um significado especial ao relatório final, o qual frequentemente não passa de um amontoado de informações. Mas, para quem acredita que a divulgação do saber tem um peso cultural tão importante quanto sua descoberta, a forma narrativa do relatório é essencial. Podemos citar o exemplo do famoso livro $O$ queijo e os vermes, de Carlo Ginzburg (1987), cuja forma narrativa foi o segredo de sua enorme difusão no mundo. Ele próprio afirma que a forma narrativa utilizada visou a levar informações científicas para o grande público, extrapolando o círculo dos especialistas sem que, no entanto, fossem banalizadas. Parece simples, mas isso exige talento científico e literário. $\mathrm{O}$ senso comum acadêmico separa em demasia o rigor científico da forma literária; esta parece até prejudicar aquela. Tal desconsideração da forma literária, de fato, esbarra na endêmica incapacidade de escrever bem.

c) Rever o processo de avaliação

As críticas dirigidas à forma como a Coordenação de Aperfeiçoamento do Pessoal de Nível Superior (CAPES) avalia os programas de pós-graduação em educação aumentam a cada dia. A assembleia final da $30^{\mathrm{a}}$ Reunião Anual da ANPEd, realizada em Caxambu em 2008, aprovou por unanimidade uma moção apresentada pelo GT Trabalho e Educação, no sentido de a ANPEd criar uma comissão para avaliar a avaliação da CAPES. Infelizmente, nem sei por quê, essa moção se perdeu no nada. Sequer lhe foi dada ampla divulgação. ${ }^{1} \mathrm{O}$ fato é que existe e alastra-se cada vez mais, no conjunto dos docentes e discentes, forte descontentamento com a forma como se avaliam os programas e suas produções.

Obviamente não se questiona a avaliação em si, mas seus pressupostos e procedimentos. De meu ponto de vista, o pressuposto mais equivocado nesse processo de avaliação é o conceito de cultura e ele subjacente. Produzir cultura não é uma atividade meramente especulativa que faz aumentar o volume de livros nas bibliotecas. É, sobretudo, um processo de identificação e projeção histórico social. É, portanto,

\footnotetext{
${ }^{1}$ A comissão foi criada durante a Assembleia Geral realizada
} na 31플 Reunião Anual, em 2009. 
conhecer mais, organizar e divulgar informações para transformar a sociedade e a natureza, humanizando-as. Ocorre que não é pela forma burocrática, determinada por regras e normas estabelecidas a priori, que se distinguem e qualificam as produções culturais, pois há produções, coletivas ou individuais, pequenas ou grandes, tradicionais ou originais, rápidas ou demoradas, precedidas por longos momentos de solitude ou realizadas em solenes eventos e congressos ou ainda em pequenos colóquios científicos etc., que podem ser relevantes culturalmente ou insignificantes, no sentido de contribuir para humanizar a sociedade e a natureza. É a história que profere a difícil sentença. Ora, a história aninha-se na sociedade dos homens e expressa-se pelas suas intricadas relações conflituosas. Não há, portanto, outro método de avaliação a não ser o método arriscado da política. Ao contrário, o estabelecimento detalhado de regras e normas burocráticas apriorísticas é a forma que melhor favorece a esperteza e a educação mercadológica.

Por isso, estabelecidas poucas e essenciais normas indispensáveis para o credenciamento dos programas de pós-graduação, ao efetuar a avaliação qualitativa, a CAPES necessita descentralizar-se administrativamente de forma que uma boa parte da avaliação possa ser realizada a posteriori, sobretudo de certas produções culturais (eventos, textos, aulas etc.). Ela poderia criar núcleos regionais, a exemplo dos centros regionais de pesquisa criados por Anísio Teixeira em 1955. É ilusão pensar que os instrumentos tecnológicos dispensem a proximidade e a interlocução humana direta, presencial; é ilusão pensar que um único escritório central em Brasília possa avaliar as pesquisas no sentido exposto. Obviamente, os núcleos regionais não dispensam a centralização nacional, porém permitem visitas e contatos frequentes dos programas de pós-graduação com os pesquisadores representativos da comunidade científica. Enfim, trata-se de criar um sistema de avaliação que articule de forma equilibrada a centralização com a regionalização e normas estabelecidas a priori com verificações feitas a posteriori.

Há risco político? Há, mas, hoje, como se faz, o risco é bem maior. d) Institucionalizar a pesquisa nas novas universidades

Emprestando sugestiva expressão de Cleide Rita Silvério de Almeida, um dos desafios da pesquisa dos programas de pós-graduação em educação é fazer com que também nas universidades do logotipo a prática da pesquisa se institucionalize, como ocorreu e ocorre nas universidades do brasão. Ora, o objetivo principal da CAPES é capacitar os profissionais do ensino superior. Os programas de pós-graduação das instituições mais jovens não possuem tradição e estrutura de pesquisa, por isso precisam institucionalizar essa prática, como fizeram, e geralmente fazem, as mais antigas universidades. Institucionalizar a pesquisa é criar uma cultura da pesquisa. Hoje, novas universidades produzem pesquisas - e frequentemente boas pesquisas. Entretanto, trata-se de pesquisas pontuais, eventuais. Uma prova de que as mais jovens universidades vivem a cultura do mero ensino é o fato de que a hora-aula é ainda, nelas, a unidade de medida do tempo-pesquisa. Nesse sentido, iniciativas interessantes são tomadas por algumas novas universidades, mas ainda há muito a fazer para criar uma cultura administrativa voltada à institucionalização jurídica, financeira e física da pesquisa.

$* * *$

Finalmente, uma palavra sobre o mestrado profissional em educação. Em maio de 2005, manifestei minhas críticas contra essa proposta. Um texto de quatro laudas foi enviado à CAPES, que gentilmente reenviou cópia a todas as coordenações dos programas de pósgraduação em educação. Hoje, a CAPES insiste na ideia de criá-lo. De um lado, receio que de fato não se queira grande expansão dos programas de pós-graduação em educação; de outro, sua excessiva centralização burocrática não permite avaliar os inúmeros cursos lato sensu. Por isso, cria-se uma terceira via. Infelizmente, muitos não se convencem de que as instituições culturais no Brasil são ainda muito rarefeitas, portanto, é salutar expandir os programas de pós-graduação acadêmicos neste imenso continente brasileiro, sem necessidade de 
recorrer aos mestrados profissionais adaptados a uma "educação prática". Do meu ponto de vista, comungo com a ideia, de que as áreas e as linhas de concentração de pesquisa dos programas de pós-graduação em educação devam ser mais bem definidas e precisadas, isto é, devam ser mais profissionais.

\section{Referências biliográficas}

ALMEIDA, Cleide Rita Silvério de. O brasão e o logotipo: um estudo das novas universidades na cidade de São Paulo. Petrópolis: Vozes, 2001.

GINZBURG, Carlo. O queijo e os vermes: o cotidiano e as ideias de um moleiro perseguido pela Inquisição. São Paulo: Companhia das Letras, 1987.

MANACORDA, Mario Aliguiero. Aos educadores brasileiros. Campinas: HISTEDBR-FE/UNICAMP, 2007.

MARX, Karl. O capital: crítica da economia política. São Paulo: Abril Cultural, 1983.

NOSELLA, Paolo. Mestrado profissional em educação?. São Carlos: UNINOVE/UFSCar, 2005, mimeo.

.; BUFFA, Ester. Instituições escolares: por que e como pesquisar. Campinas: Alínea, 2009.
TANURI, L. M. História da educação brasileira: formação do campo. Ijuí: Editora UNIJUÍ, 2005.

PAOLO NOSELLA, doutor em filosofia da educação pela Pontifícia Universidade Católica de São Paulo (PUC-SP), foi professor titular em filosofia da educação da Universidade Federal de São Carlos (UFSCar), na qual continua atuando como professor voluntário no Programa de Pós-Graduação em Educação. É também professor no Programa de Pós-Graduação em Educação da Universidade Nove de Julho (UNINOVE). Publicações recentes: A escola de Gramsci (São Paulo: Cortez, 2004); Qual compromisso político? Ensaios sobre a educação brasileira pós-ditadura (Bragança Paulista: EDUSF, 2002); em coautoria com BUFFA, Ester. Instituições escolares: por que e como pesquisar (São Carlos: Átomo \& Alínea, 2009). Pesquisa em andamento, com financiamento do CNPq: "A Escola SENAI de São Carlos, 1951-2001: um Leonardo mutilado". E-mail: nosellap@terra.com.br
Recebido em outubro de 2009

Aprovado em dezembro de 2009 
Paolo Nosella

\section{A pesquisa em educação: um balanço da produção dos programas de pós- graduação}

A pós-graduação no Brasil foi criada no ano de 1965. Antes disso, a produção das pesquisas em educação pouco se desenvolvia em instituições universitárias. Duas características fundamentais qualificam as pesquisas produzidas nos programas de pós-graduação em educação de 1965 a 1985: a escolarização da produção da pesquisa, decorrência da institucionalização da pós-graduação, e o desenvolvimento de um forte pensamento crítico, como reação aos governos militares. Os anos de 1985 até hoje se caracterizam pela consolidação e expansão da pósgraduação e as pesquisas desse período são teoricamente marcadas pela chamada crise dos paradigmas. Muitos pesquisadores, criticando os estudos sobre sociedade e educação, por não conseguirem abarcar a complexidade e a diversidade do real, partiram para a proposta de um pluralismo epistemológico e temático, privilegiando o estudo de objetos singulares. O desafio teórico hoje é articular o particular escolar (dado empírico) com o movimento geral da história (totalidade). Há também outros desafios, como aprimorar o texto ou a "narração" dos relatórios, modificar a avaliação dos programas de pós-graduação em educação feita pela CAPES e institucionalizar a pesquisa nas novas universidades do país.

Palavras-chave: educação; pesquisa; programas de pós-graduação em educação; avaliação. 
Research in education: a balance of the production of postgraduate programmes in education

In Brazil, postgraduate studies were created in 1965. Before that, the production of educational research was little developed in universities. Two main characteristics qualify the research produced in postgraduate programmes in education between 1965 and 1985: the "scholarization" of research production, a consequence of the institutionalization of postgraduate studies and the development of strong critical thinking as a reaction to the military governments. The years from 1985 until today are characterized by the consolidation and expansion of postgraduate studies and the theoretical framework of the research in this period is marked by the so called crisis of paradigms. Many researchers, who criticize the studies on society and education for not being able to cover the complexity and diversity of reality, resorted to a proposal of thematic and epistemological pluralism, privileging the studies of singular objects. Today the theoretical challenge is to articulate the specifically scholar (empirical data) with the general movement of history (totality). There are also other challenges such as how to improve the text or the "narration" of research reports, modify CAPES' system of evaluation of postgraduate programmes in education and institutionalize research in new universities of the country.

Key words: education; research; postgraduate programmes in education; evaluation.

\section{La investigación en educación: un balance de la producción de los} programas de posgrado

El posgrado en Brasil fue creada en 1965. Antes de ese año la producción de investigaciones en el campo de la Educación apenas existía en las instituciones universitarias. Las investigaciones producidas en los programas de pos-graduación en educación en el periodo de 1965 a 1985 presentan dos características fundamentales: la escolarización de la producción de la investigación como consecuencia de la institucionalización del posgrado y el desarrollo de un fuerte pensamiento crítico, como reacción a los gobiernos militares. Los años de 1985 hasta hoy se han caracterizado por la consolidación y expansión del posgrado. Las investigaciones de ese periodo están teóricamente marcadas por la llamada crísis de los paradigmas. Muchos investigadores, al criticar los estudios sobre la sociedad y la educación por no poder abarcar la complejidad y la dificultad de lo real, partieron para la propuesta de un pluralismo epistemológico y temático, dando preferencia al estudio de los objetos singulares. Desde nuestro punto de vista, el desafio teórico, hoy, es articular el particular escolar (dato empírico) con el movimiento general de la história (totalidad). Hay también otros desafios: por ejemplo, perfeccionar el texto o la "narración" de los informes, modificar la evaluación de los programas de posgrado realizada por CAPES e institucionalizar la investigación en las nuevas universidades del país. Palabras claves: educación; investigación; pos-graduación. 